\section{The risk of infection in anaesthetic practice}

Hospitals are a potentially dangerous environment for both patients and employees. The operating suite is no exception. Patients are exposed to multiple physical, chemical and microbial hazards and in turn anaesthetists and other personnel are exposed to both environmental hazards and hazards associated with patient care. Exposures may also occur outside the operating room in other areas of the hospital as well. Patterson et al. have recently reviewed occupational hazards to hospital personnel.'

While physical and chemical hazards for anaesthesia personnel are important, infectious diseases may also cause significant morbidity and occasional mortality. Fortunately, most infectious hazards can be avoided by appropriate use of available immunizations and adherence to slandard infection control practices. This paper reviews the transmission of infection to anaesthesia personnel and, while a risk-free environment can never be totally obtained, suggests appropriate methods by which infectious hazards can be minimized in the operating suite.

\section{Modes of transmission}

Modes of transmission of microorganisms from patient or the envitonment to the anaesthetist are very limited (Table I). The most hazardous, and fortunately the rarest means by which microorganisms are transmitted to the health care worker is the airborne route. Airborne spread has rarely been documented in the hospital, but highly infectious agents such as Mycobacterium tuberculosis and varicella zoster virus can occasionally be transmitted in this fashion. Respiratory droplet spread is a varjation of airborne spread but by definition the virulent organism is transmittcd in respiratory droplets within a one metre range. Mycobacterium tuberculosis, Bordatella pertussis, and rubeola (measles) are most commonly transmitted in this fashion.

Ingestion of microorganisms typically causes enteric illness such as salmonellosis or shigellosis. It is some-

TABLE I Modes of spread of microorganisms to health care workers

\begin{tabular}{ll}
\hline Mode & Example \\
\hline Airtorne & Varicella zoster virus \\
Direct contact & Herpes simplex virus \\
Droplet & M. tuberculosis \\
Ingestion & Salmonella sp. \\
Percutaneous & Hepatitis B \\
\hline
\end{tabular}

times difficult to separate food or water-borne transmission from direct contact transmission for these enteric pathogens.

Percutaneous transmission occurs when direct inoculation of the microorganism through the normally protective skin or mucous membrane accurs. Needlestick injuries, administration of a contaminated transfusion or parenteral drug abuse can lead to hepatitis $B$, non- $A$, non- $B$ hepatitis and human immunodeficiency virus (HIV) infection. Once again, it may be difficult to separate percutaneous transmission from direct contact transmission with highly virulent microrganisms.

Direct contact transmission assumes that the normal barriers to infection, such as skin, mucous membranes may not totally exclude transmission of infection. One example would be the transmission of herpes simplex virus through sexual contact or contact of hands with an open lesion or secretions (herpetic whitlow). Alternatively, microorganisms may be carried to the site of infection by the hands, such as occurs with Staphylococcus aureus or agents causing conjunctivitis. Direct contact transmission can be difficult to distinguish from droplet spread, faecalforal transmission or percutaneous transmission. Fortunately, infection control guidelines often encompass all modes of transmission for individual agents. For all practical purposes, in the practice of anaesthesia, infectious agents are transmitted only by percutaneous, direct contact and respiratory spread.

\section{Specific microorganisms}

Many pathogenic microorganisms are of potential or real importance to anaesthesia personnel. Parasites, protozoa or fungi are unlikely to be transmitted in the operating room setting and will not be discussed. Sarcoptes scabei, the agent of scabies, can be spread in the hospital, particularly when an unsuspected case of Norwegian scabies is hospitalized. However demonstration of transmission in the operating room of this agent has not been reported.

Similarly, bacterial pathogens spread by ingestion such as Salmonella sp. and Shigella sp. are of little practical

Department of Medicine, Dalhousie University and Victoria General Hospital, 1278 Tower Road, Halifax, Nova Scotia B3H 2 Y9. 
importance to anaesthetists. All health care workers, including anaesthetists, may unwillingly participate in institutional outbreaks of these infections sometimes associated with hospital cafeterias or other restaurant facilities; however, transmission in the operating room is unlikely.

A list of microorganisms potentially transmissible to anaesthesia personnel is summarized in Table Il. Some are discussed in depth below, by classification and in order of their relative importance.

\section{Viral Pathogens}

\section{HEPATITIS B}

Hepatitis $B$ is the most important viral infection to which anaesthesia personnel are exposed. Surveys of serological markers of infection in anaesthesia personnel range between 10 and 30 per cent. ${ }^{2.3}$ Studies of hepatitis B markers in other high-risk workers suggest that direct exposure to blood is the major risk factor and that age and duration of employment are other risk factors (suggesting that experience does not afford protection from infection). Anecdotal case reports of clinical hepatitis $B$ in anaesthesia personnel are common ${ }^{4,5}$ but most infections are not associated with clinical illness. The incidence of fulminant hepatitis and other chronic sequellae of hepatitis $B$ in anacsthesia personnel is unknown, but is likcly to be similar to patterns of illness in other populations studied.

TABLE II Microorganisms potentially transmissable to anaesthesia personnel from patient or environment

\begin{tabular}{ll}
\hline Organisms & Mode of transmission \\
\hline Viruses & \\
Hepatitis B* & Percutaneous \\
Hepatitis A* & Ingestion \\
Non-A, non-B hepatitis & Percutancous \\
Human immunodeficiency vinus & Percutaneous \\
Herpes simplex virus & Direct contact \\
Adenovitus* & Direct contact/droplet \\
Varicella zoster & Aittomejdroplet \\
Rubella* & Droplet \\
Rubeola (measles)* & Droplet \\
RSV & Droplevdirect contact \\
Mumps* & Droplet \\
CMV & ? Direct contact \\
Influenza A*iB & Droplet \\
& \\
Bacteria & \\
Neisseria meningitidis* & Droplet \\
Mycobacterium tuberculosis & Droplet/airbotne \\
B. pertussis* & Droplet \\
Salmonella sp. & Ingestion \\
Shigella sp. & Ingestion \\
T. pallidum & Direct contact \\
Legionella sp & Aitbarne/?ingestion \\
\hline
\end{tabular}

-Passive andior active immunization for these agents is available.
Development of hepatitis B following documented exposures from blood or body fluid on patients known to be hepatitis $B$ surface-antigen positive and e-antigen positive is likely to be as high as $20-30$ per cent in the absence of immunoprophylaxis. Because most infections occur from exposures to patients not known to be carrying the virus, the importance of minimizing exposure to blood and body fluids should be emphasized. The recent introduction of universal blood and body fluid precautions because of concerns about human immunodeficiency virus (HIV) infection should significantly lower the rate of hepatitis B among hospital personnel as an added benefit.

All anaesthesia personnel should be actively immunized against hepatitis $B$ with either the vaccine processed from the sera of hepatitis B carriers (Heptavax ${ }^{9}$ ) or the new recombinant vaccine (Recombivax ${ }^{5}$ ). Both vaccines are safe and effective, providing immunity to hepatitis $B$ for at least five years. Because of the high incidence of hepatitis B markers in anaesthesia personnel, it may be cost effective to determine the serologic status prior to immunization. Pre-existing hepatitis $\mathbf{B}$ antibody or chronic hepatitis B carriage would eliminate the need for immunization. Unfortunately, studies of hospital personncl determined to be at high risk for hepatitis $B$ infection suggest that acceptance of immunization is suboptimal. ${ }^{6}$

\section{HUMAN IMMUNODEFICIENCY VIRUS (HIV)}

This virus is much less infectious than hepatitis $B$ as it is present in far smaller quantities in the serum of infected patients in comparison to hepatitis B. However, there is no current immunization against HIV and the sequellae of the infection may be more serious. No case reports of transmission of the buman immunodeficiency virus to anaesthesia personnel are available but the issues of AIDS and anaesthesia have been reviewed recently, ${ }^{7-9} \mathrm{~A}$ number of ancciotal case reports of transmission of HIV in the health care setting have been published. However, several large prospective studies of health care workers in the United States ${ }^{10}$ and in Canad $a^{11}$ have not documented infection in anaesthesia personnel from work-related exposures, although information from these surveys has not been stratified by medical or surgical specialty (RA Marcus, K. Elmslie, personal communications). These prospective studies suggest that percutaneous exposure to blood or body fluids has a risk of infection of between 1-10/1000 in comparison to hepatitis B where the risk may be as high as 100-300/1000 exposures.

Because the epidemiology of HIV infection is similar to that for hepatitis $B$, the introduction of universal blood and body fluid precautions should go far in eliminating the risk of HIV transmission to anaesthesia personnel. However this will require changes in the traditional practice of 
many anaesthetists who have not used gloves when starting intravenous or intraarterial lines or who don't wear eye glasses or goggles for intubations. Mandatory screening programs for hospital admissions or for patients undergoing surgery are not currently recommended as a means to limit exposure to HIV in the operating room.

\section{NON-A, NON-B IEEPATITIS}

Non-A, non-B hepatitis has been transmitted in the health care setting, ${ }^{12.13}$ and is the most important cause of transfusion-associated hepatitis today. More than one agent is responsible and at least one form of the infection has epidemiologic similarities to hepatitis B. No anaesthesia personnel have been reported to have acquired this infection, but this infection should be as common or more common than hepatitis $\mathrm{B}$ in anacsthesia personnel. Because the epidemiology is similar to hepatitis B, universal blood and body fluid precautions should limit the acquisition of non- $A$, non-B hepatitis in anaesthetic practice.

\section{HERPES SIMPLEX VIRUS}

Herpetic whitlow, usually caused by herpes simplex virus, Type 1 , is a frequently found and often misdiag. nosed infection in hospital personnel. ${ }^{14}$ Herpes simplex virus is excreted in the oral secretions of severely ill patients whether active lesions are present or not. Herpetic whitlow is especially common in personnel whose ungloved hands are exposed to oral secretions. Respiratory therapists, dentists, and anaesthetists are at high risk and a case report has been published of this condition in an anaethestist. ${ }^{15}$ Percutaneous inoculation does not seem to be necessary as with HIV or hepatitis B, although disruption of skin around the nailbed may play some role in promoting the acquisition of infection.

Although no vaccine is currently available for preventing this occupational hazard, oral acyclovir may be helpful in minimizing morbidity associated with recurrent outbreaks or in preventing frequently occurring outbreaks. Universal blood and body fluid precautions with appropriate gloving should prevent this annoying infection. Gloving is also mandatory to prevent the spread of infection to patients ${ }^{16}$ when active lesions are present.

\section{VARICELLA-ZOSTER VIRUS (VZV)}

Varicella zoster virus (VZV), another human herpes virus, appears to be much more contagious than herpes simplex virus and in addition to direct contact spread, airborne and droplet spread of this infection are common. Fortunately, over 90 per cent of the general population acquires life-long immunity during childhood to this infection and nosocomial acquisition of VZV infection is rare.

Outbreaks of nosocomial VZV have been frequently reported but primarily affect children ${ }^{17}$ or severely immunosuppressed patients. ${ }^{18}$ It is possible and reported that varicella can occur in non-immune staff, however. ${ }^{17,18}$ Whether hospital employees should be screened for prior immunity to VZV by skin test or serology is controversial ${ }^{19}$ but anaesthesia personnel should be aware of the risk of infection during intubation of patients with active shingles, disseminated varicella, or varicella pneumonia. Where possible, anaesthesia personnel not immune to varicella should be excluded from patient contact wherc airborne or droplet spread is likely. Otherwise masks, gloves, and gowns should be mandatory, and may help limit transmission to non-immune staff.

\section{RUBEOLA (MEASLES)}

The transmission of measles in hospital settings has been reviewed recently. ${ }^{20}$ Approximately one-quarter of measles cases transmitted in hospital are to personnel rather than to patients. Index cases are usually patients and rarely are other staff responsible for transmission to other hospital staff. Although measles is spread by the respiratory droplet route, data are not available to confirm the risk to anaesthesia personnel from procedures involving intubation. Most individuals bom before 1957 are considered immune and immunization for those born after this date is recommended. In surveys, up to ten per cent of hospital employees are non-immune and routine measles immunization should be mandatory on employment for personnel who have no record of immunization and were born after 1957.

\section{RUBELLA}

Rubella, another immunizable childhood disease, has also been transmitted in the hospital setting ${ }^{21-22}$ and is more likely than measles to spread from staff to other staff, rather than from patient to staff. No specific discussion of the risk to anacsthesia personnel has been published. However up to 15 per cent of all hospital employees are not immune to rubella and rubella antibody screening for new hospital employees with subsequent immunization of susceptibles is recommended. Unfortunately, physicians have been notoriously poor responders to suggestions that they be immunized for rubella ${ }^{23}$ as well as for hepatitis B.

\section{CYTOMEGALOVIRUS (CMV)}

Human cytomegalovinus (CMV) infection is extremely common; $60-80$ per cent of the population over the age of 30 possess CMV antibody reflecting previous and now 
latent infection. Excretion of CMV by hospitalized patients is common but studies of cytomegalovirus as an occupational hazard to nursing and other hospital personnel have not demonstrated an increased risk of infection. ${ }^{24.25}$ No studies to demonstrate an increased risk of primary cytomegalovirus infection in anaesthesia personnel have been published but the risk is also probably low. Restriction endonuclease analyses of paired isolates where transmission from patient to worker have been suspected often show that infection was acquired outside the hospital. Direct contact transmission should be eliminated by both the institution of universal blood and body fluid precautions as well as careful hand washing before and after patient care.

\section{RESPIRATORY VIRUSES}

Nosocomial outbreaks of adenovirus ${ }^{26,27}$ respiratory syncytial virus ${ }^{28}$ and influenza $a^{29}$ infections have been reported. Adenovirus conjunctivitis appears to be a more common problem than respiratory tract infection while the other viruses cause primarily lower and upper respiratory tract infection respectively. In particular, influenza A and $B$ outbreaks may cause significant morbidity and absenteeism, if not mortality among hospital employees. Anaesthesia personnel have not been specifically identificd as a risk group but intimatc cxposurc to respiratory secretions would suggest that the risk might be higher than for other employees with less direct exposure. Masking, gloves and careful hand washing should be employed when undifferentiated respiratory tract infection is present in the patient being cared for by the anaesthetist.

Vaccines are available for a few adenovirus strains but are not currently recommended for general use. Vaccines for respiralory syncytial virus are under development. When epidemic influenza $A$ or $B$ is identified in the community, immunization with the current vaccine formulation is recommended for all hospital personnel. ${ }^{30}$ Anaesthesia personnel with underlying medical conditions may also be eligible for yearly immunization whether epidemic disease is present or not. Short-term chemoprophylaxis with amantidine may be warranted as an adjunct to immunization during explosive outbreaks of influenza $A$ in the hospital ${ }^{30}$ This may prevent or ameliorate infection until immunization provides immu nity at seven to ten days.

\section{MUMPS}

Outbreaks of nosocomial mumps virus infection are exceedingly rare and transmission appears to be by direct contact with respiratory secretions. ${ }^{32}$ Spread to hospital personnel has not been documented but is theoretically possible. Anaesthesia personnel with a largely paediatric practice should be aware of potential exposures to mumps virus and in the absence of a history of immunity, should consider immunization.

\section{Bacterial diseases}

Several bacterial diseases have been transmitted in the health care setting. Because effective treatments are often available for bacterial infections, health care workers express less concern about potential exposures to bacterial pathogens than to hepatitis B or HIV infection. However, the use of appropriate infection control procedures effective in preventing viral infections should also minimize the risk of acquiring bacterial pathogens as well.

\section{MYCOBACTERIUM TUBERCULOSIS}

Patients with active cavitary pulmonary tuberculosis can be extremely effective disseminators of Mycobacterium tubercuiosis in the hospital environment. ${ }^{33}$ While droplet spread is more common, airbome spread of tuberculosis has been documented in the hospital setting. ${ }^{34} \mathrm{~A}$ review of nosocomial tuberculosis specifically in physicians has been published. ${ }^{35}$ Highest rates of infection, as documented by tuberculin tests, were in the primary care specialties. Anaesthetists while not specifically identified in published studies, probably have an overall prevalence of infection of ten per cent. Almost 50 per cent of exposures that lead to skin test conversion are not identified and yearly conversion rates for tuberculosis (with geographic differences) approach two per cent per year. Under these circumstances, anaesthesia personne] should be skin tested when beginning their employment and then yearly. In areas where tuberculosis appears to be very rare, yearly skin testing may not be warranted for anaesthesia personnel. Yeurly chest roentgenograms are not indicated in tuberculin negative patients and repeat skin testing of tuberculin positive individuals is not necessary. The use of BCG immunization is controversial and is probably not warranted in North America except under circumstances of predictably high exposure to populations with high rates of infection (for example native communities).

\section{BORDETELEA PERTUSSIS}

Outbreaks of pertussis among patients and staff in paediatric hospitals have been described ${ }^{36}$ and can cause serious morbidity. Anaesthesia personnel have not been specifically identified as cases in such outbreaks but may be exposed. Adults may be susceptible despite adequate childhood immunization presumably because of waning immunity.

Because this problem is rare, no specific precautions are necessary and outbreaks when identified should be 
managed by the use of prophylactic erythromycin and appropriate isolation. Adult immunization with the currently available pertussis vaccine is controversial because of the frequent and significant side effects associated with immunization of adults. ${ }^{36}$ Newer vaccines will be available soon and may be useful in preventing nosocomial spread of Bordatella pertussis when outbreaks are identified.

\section{NEISSERIA MENINGITIDIS}

Anaesthesia personnel may be called to assist in intubation of patients with fulminant meningococcemia or meningococcal meningitis. In addition exposures 10 patients with Neisseria meningitidis pneumonia in the ICU may accur on occasion. Evidence suggesting nosocomial transmission of meningococci $i^{37,38}$ is scanty but hospital personnel exposed to respiratory secretions of these patients are theoretically at risk of developing invasive meningococcal disease. Respiratory isolation is appropriate and rifampin chemoprophylaxis may be used when obvious respiratory droplet/close contact exposures have occurred. Pharyngeal carriage of meningococci is common in the general population and throat swabs are not useful in confirming exposure.

Although vaccines against several serotypes of Neisseria meningitidis are available, routine pre-exposure use of these vaccines in anaesthesia personnel or other employees is not warranted. Selective use of type-specific vaccines in the setting of community outbreaks of meningococcal disease are warranted as an adjunct to chemoprophylaxis and may be used in hospital employees where significant exposure has occurred.

\section{Summary}

Infectious hazards to anaesthesia personnel are real but the appropriate use of immunization, universal blood and body fluid precautions, and respiratory precautions where appropriate, should minjmize the risk of infection at work. In particular, the resistance of physicians to immunization, especially to hepatitis $B$, needs to be changed. Protection against other blood-bome pathogens for which immunization is not available, such as HIV, may also depend on the willingness of anaesthesia personnel to accept and carry out recommendations for universal blood and body fluid precautions. Regulatory agencies and compensation boards are likely to look closely at adherence to established guidelines when determining benefits for work-related infections. Complaints that the routine use of gloves interferes with anaesthetic practice are frequent but unacceptable in the current climate and it behooves the profession to ensure that compliance with currently accepted infection control guidelines is complete.

\section{References}

1 Patterson WB, Craven DE, Schwartz DA et al. Occupational hazards to hospital personnel. Ann Int Med 1985; 102: 658-80.

2 Berry AJ, Isaacson IJ, Kane MA et al. A multicenter study of the prevalence of hepatitis B viral serologic markers in anaesthesia personnel. Anesth Analg 1984; 63: 738-42.

3 Denes AE, Smith JL, Maynard JE et al. Hepatitis B infection in physicians: results of a nationwide seroepidemiologic survey. JAMA 1978; 239: 210-2.

4 Shanson DC. Hepatitis B oubreak in operating-theatre and intensive care staff, Lance: 1980; 12: 596.

5 Moss ALH. Hospital outbreak of bepatitis B. NZ Med J 1981; 94: 65-6.

6 Klimeí $J J$, Brettman L, Neuhaus E, Garibaldi RA. A multihospital hepatitis B vacine program: prevalence of antibody and acceptance of vaccination among high risk hospital employees. Infect Control 1985; 6: 32-4.

7 Cordero AS, Bonner JT, Byrnes RK. AIDS and the anaesthetist. Can Anaesth Soc J 1985; 1332: 45-8.

8 Lee KG, Soni $N$. AIDS and anaesthesia. Araesthesia 1986; 41: 1011-6.

9 Arden J. Anesthetic management of patients with AIDS. Anesthesiology $1986 ; 64: 660-1$.

$10 \mathrm{CDC}$. Update. Human immuodeficiency virus infections in health-care workers exposed to blood of infected patients. MMWR 1987; 36: 285-9.

11 LCDC. National survellance program on occupational cxposure to the human immundeficiency virus among health care workers in Canada. Can Med Assoc J 1988; 138: 31-3.

12 Meyers $J D$, Dienstag JL, Purcell RH, Thomas ED. Holmes $K K$. Parenterally transmitted non- $A$, non-B hepatitis: an epidemic revisited. Ann Int Med 1977; 87: 57-9.

13 CDC. Non-A, non-B hepatitis infection transmitted via a needle. Washington. MMWR 1979; 28: 150-8.

14 Greaves WL, Kaiser AB, Alford RH, Schaffner W. The problem of herpetic whitlow among hospital personnel. Infect Control 1980; 1: 3181-5.

15 Orkin FK. Herpetic whitlow - occupational hazard to the anesthesiologist. Anesthesiology 1970; 33: 671-3.

16 Adams G. Stover BH, Keenlyside RA et al. Nosocomial herpetic infections in a pediatric intensive care unit. Am J Epid 1981; 113: 126-32.

17 Leclair JM, Zaia JA, Levin MJ, Congdon RG, Goldmann $D A$. Airborne transmission of chicken pox in a hospital. N Engl J Med 1980; 302: 450-3.

18 Morens DM, Bregman DJ. West CM et al. An outbreak of varicella-zoster virus infection among cancer patients. Ann Int Med 1980; 93: 414-9.

19 Weitekamp MR, Schan $P, A b e r R C$. An algorithm for the control of nosocomial varicella-zoster virus infection. Am J Infect Cotrol 1985; 13: 193-8. 
20 Davis RM, Orenstein WA Frark JA. Transmission of measles in medical settings: 1980 through 1984. JAMA 1986; 255: 1295-8.

21 Polk BF, White JA, De Girolausi PC, Modlin JF. An outbreak of rubella among hospital personnel. $N$ Engl J Med 1980; 303: 541-5.

22 Strassburg MA, Stephenson TG. Habel LA, Fannin SL. Rubella in hospital employees. Infeet Control 1983; 5: 1123-6.

23 Orenstein WA, Heseltime PNR, Legagnoux SJ, Portnoy $B$. Rubella vaccine and susceptible hospital employees: poor physician participation. JAMA 1981; 245: 711-3.

24 Dworsky ME. Welch K. Cassady G, Stagno S. Occupational risk for primary cytomegalovirus infection among pediatric health caseworkers. N Engl J Med 1983; 309: $950-3$.

25 Canadian Pediatric Society. Cytomegalovirus: an occupational hazard? Can Med Assoc J 1984; 1131: 730.

26 Levandowski RA, Ruberis $M$. Nosocomial conjunctivitis caused by adenovirus type 4 . J Inf Dis 1981; 143: 28-31.

27 Straube RC. Thompson MA, Van Dyke RB. Adenovins type $7 \mathrm{~b}$ in a children's hospital. J Inf Dis 1983; 147 . 814-9.

28 Hail CB. Dongras RG, Geiman JM et al. Nosocomial respiratory syncytial yirus infections. N Engl J Med 1975; 293: 1343-6.

29 Blumenfeld HL, Kilbourne ED, Louria DB, Rogers DE. Studies on influenza in the pandemic of 1957-1958: an epidemiologic, clinical and serologic investigation of an intrahospital epidemic with a note on vaccination efficacy. J Clin Invest 1959; 38: 199-212.

30 Heffman PC, Dixon RE. Control of influenza in a hospital. Ann Intern Med 1977; 87: 725-8.

31 O'Donaghue JM, Roy CG. Terry DW, Beatty $H N$. Prevention of nosocomial influenza infection with amantadine. Am J Epidem 1973; 97: 276-82.

32 Burnell PA, Birckman A, O'Hare D, Steinberg $S$. Ineffectiveness of isolation of patients as a method of preventing mumps. N Engl J Med 1968; 279: 1357-61.

33 Catanzaro A, Nosocomial tuberculosis. Am Rev Respir Dis 1982; 125 : 559-62.

34 Ehrenkranz NJ, Kicklighter JL. Tuberculosis outbreak in a general hospital: evidence for airbome spread of infection. Ann Int Med 1972; 77 : 377-82

35 Barrett-Connor $E$. The epidemiology of tuberculosis in physicians. JAMA 1979; 241: 33-8.

36 Linnemann CC, Ramundo N, Perlstein PH et al. Use of pertussis vaccine under epidemic involving hospital staff. Larcet 1975; 2: 540-3.
37 Cohen MS, Steere AC, Baltimore R. Possible nosocomial transmission of group Y Neisseria meningitidis among oncology patients. Ann Int Med 1979; 91: 7-12.

38 Rose HD, Lenz IE. Sheth NK. Meningococcal pneumonia: a source of nosocomial infection. Arch Int Med 1978; 141: $575-7$. 